\title{
Mide kanseri deneyimlerimiz: Tanı ve tedavide geç mi kalıyoruz?
}

\author{
Our stomach cancer experiences: is there any retardation in diagnosis or treatment?
}

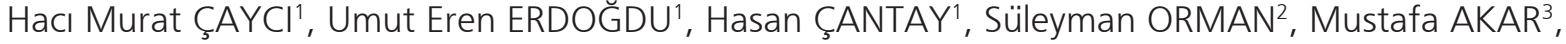 \\ Hakan DEMIRCi4 \\ T.C. Sağlık Bilimleri Üniversitesi Bursa Yüksek Ihtisas Eğitim ve Araştırma Hastanesi, ' Genel Cerrahi Kliniği, ${ }^{3}$ Gastroenteroloji Kliniği, \\ ${ }^{4}$ Aile Hekimliği Kliniği, Bursa \\ ${ }^{2}$ İstanbul Medeniyet Üniversitesi Göztepe Eğitim Araştırma Hastanesi, Genel Cerrahi Kliniği, İstanbul
}

\begin{abstract}
Giriş ve Amaç: Mide kanserinin erken tanınması tedavide daha sınırlı rezeksiyonların yapılmasına ve sağ kalımın iyileşmesine olanak sağlar. Amacımız mide kanserli hastalarımızın semptomları, endoskopik bulguları ve ameliyat piyeslerini değerlendirerek hangi evrelerde başvurduklarını saptamaktır. Gereç ve Yöntem: Mide kanseri nedeniyle elektif opere edilen 77 hastanın verileri retrospektif olarak değerlendirildi. Hastaların demografik verileri, ko-morbiditeleri, tümör lokalizasyonları, pasaj geçişinin olup olmadı̆̆ı, semptomlar ve süreleri, endoskopik patoloji sonuçları, Amerikan Anesteziyoloji Derneği sınıflaması, uygulanan rezeksiyon tipleri, patolojik evreler, tümör büyüklügü, çıkarılan ortalama lenf nodu ve metastatik lenf nodu sayısı ve evreleri değerlendirildi. Bulgular: Çalışmamızda, olguların 55'i $(\% 71,4)$ erkek, 22'si $(\% 28,6)$ kadın idi. Olguların 46'sına $(\% 59,8)$ total gastrektomi, 16'sına (\%20.8) subtotal gastrektomi ve $15^{\prime}$ ine de $(\% 19,4)$ eksploratif laparotomi uygulandı. Laparoskopik yaklaşımla $2(\% 2,6)$ olguya total gastrektomi, 2 $(\% 2,6)$ olguya subtotal gastrektomi yapıldı. Olguların 9'unda $(\% 11,68)$ ek organ rezeksiyonu yapıldı. Morbidite $9(\% 11,6)$ olguda görüldü. Mortalite $3(\% 3,9)$ olguda görüldü. En sık saptanan T patolojik evresi pT3 ve pT4 idi (sırasıyla \% 18,2 ve \%55,8). Olgularımızın büyük çoğunluğunun Evre 3 (\%61) oldukları görüldü. Sonuç: Mide kanseri nedeniyle ile ameliyat edilen hastalarımız tanı sırasında genellikle ileri evrede olup, bu hastalara geniş çaplı mide rezeksiyonları ve lenf nodu diseksiyonları yapılmaktadır. Minimal cerrahi girişimlerin veya endoskopik girişimlerin uygulanabilmesi için tarama programları ile olguların erken evrede saptanması gereklidir.
\end{abstract}

Anahtar kelimeler: Mide kanseri, cerrahi, evre, endoskopik tarama

\section{GíRiş}

Mide kanseri dünya genelinde dördüncü sıklıkta görülen kanser tipi olup, kanserle ilişkili ölümlerde üçüncü sırada yer almaktadır (1). Dünya genelinde yeni tanı alan kanserlerin $\% 8^{\prime} i$ ve kanser nedeniyle olan ölümlerin $\% 10^{\prime}$ u mide kanserine bağlı olmaktadır (2). Olguların 3/4'ü gelişmiş ülkelerde özellikle uzak doğu ülkelerinde (Kore, Japonya ve Çin) görülürken özellikle ABD ve Batı Avrupa'da mide kanserinin görülme insidansı giderek azalmaktadır ve Doğu Asya'nın insidansının sadece altıda biridir. Ülkemiz kanser
Background and Aims: Early diagnosis of gastric cancer allows for limited resection and improved survival. Our aim is to evaluate the symptoms, endoscopic findings and surgical procedures of our patients with stomach cancer and to determine at which stage they are applying. Materials and Methods: The data of 77 patients who were operated for gastric cancer were evaluated retrospectively. Patients' demographic data, co-morbidities, tumor localization, presence or absence of passage, symptoms, and duration, endoscopic pathology results, American Society of Anesthesiologist, type and method of resection applied, pathologic stage, tumor size, the number of lymph nodes removed, the number of metastatic lymph nodes and stages were evaluated. Results: In our study, 55 (71.4\%) male and 22 (28.6\%) women were included. Total gastrectomy was performed in 46 patients (59.8\%), subtotal gastrectomy in 16 patients (20.8\%) and explorative laparotomy in 15 patients (19.4\%). Two patients (2.6\%) underwent total gastrectomy with the laparoscopic approach and subtotal gastrectomy in two patients(2.6\%). In nine (11.68\%) cases, additional organ resection was performed. Morbidity was seen in nine patients (11.6\%) and mortality was seen in 3 cases(3.9\%). The most frequent pathologic stages were pT3 and pT4 (18.2\% and $55.8 \%$, respectively). It was seen that the majority of our cases were in Stage 3 (61\%). Conclusion: Our patients who are operated due to gastric cancer are usually in an advanced stage during diagnosis and they have extensive gastric resections and lymph node dissections. In order to be able to perform less invasive surgical procedures or endoscopic procedures, it is necessary to detect the cases at an earlier stage with screening programs.

Key words: Gastric cancer, surgery, stage, endoscopy, screening

tarama programında olmamasına rağmen mide kanseri; kadın hastalarda meme kanseri, erkek hastalarda akciğer kanserinden sonra ikinci sırada görülmektedir (3). Genel olarak, erkekler kadınlara göre iki kat daha sıklıkla etkilenir ve ortalama görülme yaşı 60-70 yaş arasındadır (4).

Helicobacter pylori enfeksiyonu, tütsülenmiş veya tuzlu gıdalar, pernisiyöz anemi, daha önceden geçirilmiş mide cerrahisi, kronik atrofik gastrit, intestinal metaplazi, ge-

iletişim: Hacı Murat ÇAYCI

T.C. Sağlık Bilimleri Üniversitesi Bursa Yüksek Ihtisas Eğitim ve Araştırma Hastanesi, Genel Cerrahi Kliniği, Bursa, Türkiye 
netik kanser sendromları [herediter nonpolyposis kolon kanseri (HNPCC), Li-Fraumeni sendromu, Peutz-Jeghers sendromu ve herediter diffüz gastrik kanser (HDGC) sendromu] belirgin mide kanseri için belirgin risk faktörleridir (4-7).

Mide kanserli olgularda 5 yıllık sağ kalım tüm agresif tedavilere rağmen \%30 seviyesindedir (8). Kötü prognozun en önemli nedeni tanının geç evrelerde konulmasıdır (9). Erken evrelerde asemptomatik olan mide kanseri ileri evrelerde kilo kaybı, epigastrik ağrı veya rahatsızlık, gastrointestinal kanama, kusma ve anoreksiyaya neden olur. Japonya ve Kore'de, mide kanseri için yüksek bilinçlilik ve yaygın endoskopik tarama, erken mide kanseri olan hastaların (örn. T1 tümörleri) oranının \%50'ye ulaşmasına neden olmuştur. Ne yazık ki, diğer ülkelerde mide kanserine sıklıkla ileri evrelerde tanı konulur (10).

Mide kanserinde sağ kalımın iyileşmesi ve mortalitenin azalması için tarama ve sağ kalım programları ile erken evrede tanı konması büyük önem taşımaktadır. Kanser gelişimini önlemek için primer yaklaşım olan Helicobacter pylori eradikasyonu önemlidir (Literatür). Ancak Helicobacter pylori ile enfekte ve premalign lezyonu olan her hastada mide kanseri gelişmediği için tarama programları iyi planlanmalıdır. Ne zaman ve nasıl tarama programlarının başlayacağı ve yapılacağı ülkelere göre farkılıı göstermektedir. Sekonder önleyici yaklaşım premalign mide lezyonlarının endoskopi ile taranmasıdır. Mide kanseri tanısında endoskopik tarama altın standarttır. Endoskopik tarama ile erken evre mide kanseri teşhisi sağlanmakta ve mortalite azalmaktadır (11).

Bu retrospektif çalışmada amacımız mide kanserli hastalarımızın semptomlarını, endoskopik bulgularını ve ameliyat piyeslerini değerlendirerek hangi evrelerde başvurduklarını saptamaktır.

\section{GEREÇ ve YÖNTEM}

Ocak 2013- Haziran 2016 tarihleri arasında T.C. Sağlık Bilimleri Üniversitesi Bursa Yüksek Ihtisas Eğitim ve Araştırma Hastanesinde mide kanseri nedeniyle elektif koşullarda ameliyat edilen 77 hastanın verileri retrospektif olarak incelenerek, demografik verileri, semptomları, endoskopik bulguları, ko-morbid hastalıkları, mide rezeksiyon ameliyat tipleri, patolojik evreleri [tümör, node, metastaz (TNM)] değerlendirildi. Hastalara operasyon öncesi detaylı bilgi verildi ve sonrasında yazııı aydınlatılmış onam alındı. Çalışmamız Dünya Helsinki Bildirgesi'ne uygun olarak yazıldı.

Tüm hastalar ameliyat öncesinde nutrisyonel durum ve Amerikan Anesteziyoloji Derneği (ASA) sınıflaması yönün- den değerlendirildi. Nutrisyonel durumu bozuk olan hastalara (son altı ayda vücut ağırlığııın \%10'undan fazlasını kaybeden veya obstrüksiyon nedeniyle oral alımı kısıtlı olan) en az 15 gün süre ile parenteral ve gereğinde enteral nutrisyon desteği verildi. Operasyondan önceki akşam tüm hastalara derin ven trombozu profilaksisi için düşük molekül apırlıklı heparin (Enoxaparine) subkutan olarak uygulandı ve ameliyat öncesinde de varis çorabı giydirildi.

Orta veya distal mide yerleşimli tümörlü hastalarda distal veya subtotal gastrektomi, proksimal yerleşimli tümörlerde ise total gastrektomi yapıldı. Lenf nodu diseksiyonunun genişliği Japon Mide Kanseri Tedavi Rehberi (3. Ingilizce baskı) önerilerine göre yapıldı (12). Diffüz tip tümörler için en az $8 \mathrm{~cm}$, intestinal tip tümörler için en az $5 \mathrm{~cm}$ 'lik tümörsüz cerrahi sınır elde edilmesine dikkat edildi. Patolojik evreleme UICC/TNM 7. sürümünde önerilen TNM evreleme sistemine göre yapıldı. Subtotal gastrektomi sonrasında Billroth II rekonstrüksiyonu yapıdı. Total gastrektomi sonrası rekonstrüksiyon, jejunal poş olmadan bir Roux-en-Y özofagojejunostomi ile yapıldı.

Postoperatif dönemde herhangi bir problem gelişmeyen subtotal gastrektomili hastalara da 3. gün oral gıdaya geçildi. Total gastrektomili hastalara 5. gün pasaj grafisi çekilmesini takiben kaçak saptanmadığı takdirde oral gıda başlandı.

\section{İstatiksel Analiz}

Çalışmada sürekli değişkenlerin normal dağılıma uygunluğu Shapiro Wilk testi ile incelenmiştir. Sürekli değişkenler normal dağılıma uygunluk göstermesi durumunda ortalama sstandart sapma, normal dağılıma uygunluk göstermemesi durumunda ise medyan (minimum-maksimum) değerleriyle ifade edilmiştir. Kategorik değişkenler $\mathrm{n}(\%)$ değerleriyle ifade edilmiştir. Verilerin değerlendirmesinde SPSS (IBM Corp. Released 2013. IBM SPSS Statistics for Windows, Version 22.0. Armonk, NY: IBM Corp.) programı kullanıımışır.

\section{BULGULAR}

Çalışmamızda olguların 55'i $(\% 71,4)$ erkek, 22'si $(\% 28,6)$ kadın olup ortalama yaş $64,40 \pm 10,26$, ortalama beden kitle indeksi (BMI) değeri 26 $\pm 4,07$ idi. Olguların demografik özellikleri, ko-morbid hastalıkları ve ASA skorları Tablo 1'de gösterilmektedir. Ko-morbid hastalıklar olarak hipertansiyon $16(\% 20,7)$ olguda, tip 2 diabetes mellitus ve hipertansiyon birlikteliği $9(\% 11,6)$ olguda, tip 2 diabetes mellitus $8(\% 10,4)$ olguda, koroner arter hastalığı $7(\% 9,09)$ olguda ve kronik obstrüktif akciğer hastalığı (KOAH) $3(\% 3,9)$ olguda görüldü. ASA 2 skoruna sahip olgular daha fazla idi. 


\begin{tabular}{|c|c|}
\hline & n (\%) \\
\hline Yaş & $64,40 \pm 10,26$ \\
\hline Cins $K / E$ & $22(\% 28,6) / 55(\% 71,4)$ \\
\hline $\mathrm{BMI}$ & $26 \pm 4,07$ \\
\hline Ko-morbidite & $41(\% 53,2)$ \\
\hline ASA & \\
\hline 2 & $53(\% 68,8)$ \\
\hline 3 & $24(31,2)$ \\
\hline
\end{tabular}

K: Kadın, E: Erkek, BMI: Beden kitle indeksi, ASA: American Society of Anesthesiologist

Tablo 2. Tümör özellikleri

\begin{tabular}{|l|c|}
\hline & $\mathbf{n ~ ( \% )}$ \\
\hline Tümör Lokalizasyonu & \\
Antrum & $24(\% 31,2)$ \\
Korpus & $28(\% 36,4)$ \\
Kardiya & $25(\% 32,5)$ \\
\hline Pasaj obstrüksiyonu & $13(\% 16,9)$ \\
\hline Semptomlar & \\
\hline Epigastrik ağrı & $42(\% 54,5)$ \\
Kusma & $17(\% 22,1)$ \\
Anemi & $8(\% 10,4)$ \\
Disfaji & $5(\% 6,5)$ \\
Dispepsi & $5(\% 6,5)$ \\
\hline Semptom süresi (ay) & $3(1-24)$ \\
\hline Preoperatif patoloji & $75(\% 97,4)$ \\
Adenokarsinom & $2(\% 2,6)$ \\
\hline HGD & \\
\hline
\end{tabular}

HGD: yüksek dereceli displazi

Tablo 3. Operasyon tipi ve metodu, morbidite ve mortalite

\begin{tabular}{|l|c|}
\hline Operasyon Tipi & \\
\hline Total gastrektomi & $46(\% 59,8)$ \\
\hline Subtotal gastrektomi & $16(\% 20,8)$ \\
Eksploratif laparotomi & $15(\% 19,4)$ \\
\hline $\begin{array}{l}\text { Operasyon Metodu } \\
\text { Laparoskopi }\end{array}$ & $4(\% 5,2)$ \\
\hline Açık cerrahi & $68(\% 88,4)$ \\
Konversiyon & $5(\% 6,4)$ \\
\hline Morbidite & $9(\% 11,6)$ \\
\hline Mortalite & $3(\% 3,9)$ \\
\hline Hastanede kalış süresi (gün) & $6,2(5-17)$ \\
\hline
\end{tabular}

Endoskopik olarak tümör yerleşim yerleri ve pasaj geçişi, semptom ve süreleri, preoperatif patoloji sonuçları Tablo 2 'de gösterilmiştir. Semptomların ortalama süresi 3 ay (124 ay) idi. Olgularda başvuru sırasında en sık saptanan semptomlar karın ağrısı ve kusma idi (sırasıyla \%54,5 ve $\% 22,1)$. Tümör lokalizasyonunun antrum, korpus ve kardiyada benzer oranda olduğu görüldü. Olguların 13'ünde $(\% 16,9)$ endoskopun geçişine engel olan darlık saptandı. Preoperatif dönemde sadece iki olguda patalojik tanı yüksek dereceli displazi (HGD) idi.

Olguların 46'sına $(\% 59,8)$ total gastrektomi, 16'sına $(\% 20,8)$ subtotal gastrektomi ve $15^{\prime}$ ine de $(\% 19,4)$ eksploratif laparotomi yapıldı (Tablo 3). Olguların 9'unda $(\% 12,9)$ rezeksiyon için laparoskopik girişim yapılması düşünüldü. Rezeksiyonların 4'ü laparoskopik yöntemle tamamlandı $(2(\% 2,6)$ total gastrektomi, $2(\% 2,6)$ subtotal gastrektomi). Olguların $5^{\prime}$ inde $(\% 6,4)$ laparoskopiden açık yönteme geçildi. İntraoperatif dönemde dalaktan kanama nedeniyle $1(\% 1,3)$ olguya splenektomi, middle kolik arter yaralanması nedeniyle $1(\% 1,3)$ olguya sağ hemikolektomi yapıldı. Eksplorasyonda pankreas gövde invazyonu bulunan $2(\% 2,6)$ olguya distal pankreatektomi ile birlikte splenektomi ayrıca total gastrektomi esnasında dalak hilusunda tutulum olan $5(\% 6,5)$ olguya da splenektomi uygulandı.

Çalışmamızda morbidite $9(\% 11,6)$ hastada gelişti (Tablo 3). Yara yeri enfeksiyonu $2(\% 2,6)$ olguda, evisserasyon 2 $(\% 2,6)$ olguda, subileus $1(\% 1,3)$ olguda, kalp yetmezliği $1(\% 1,3)$ olguda, serebellar infarktüs $1(\% 1,3)$ olguda, pankreas fistülü $1(\% 1,3)$ olguda ve pnömoni $1(\% 1,3)$ olguda görüldü. Morbidite nedeniyle reoperasyon uygulanmadı, medikal tedavi uygulandı. Mortalite $3(\% 3,9)$ olguda görüldü (Tablo 3). Cerrahi işleme bağlı mortalite gözlenmedi. Olguların 1 'i $(\% 1,3) 48$. saatte akut myokard infarktüsü, 1'i $(\% 1,3)$ postoperatif 20 . günde kalp yetmezliği ve $1^{\prime} i$ de $(\% 1,3)$ postoperatif 6 . günde serebellar infarktüs nedeniyle kaybedildi.

Hastalarımızın ortalama tümör boyutu, T evreleri, çıkarılan ortalama total lenf nodu ve metastatik lenf nodu sayıları ve TNM sistemine göre evreleri Tablo 4'de gösterilmiştir. Olgularımızda ortalama tümör çapı $6 \mathrm{~cm}$ olup en sık rastlanan T evreleri sırasıly T4 ve T3 ve $(\% 55,8$ ve $\% 18,2)$ idi. Lenf nodu diseksiyonu ile ortalama 24,38 \pm 7,54 lenf nodu çıkarıldı. Metastatik lenf nodu sayısı ortalama 9,79 (1-34) saptandı. Olgularımızın en sık Evre 3 oldukları görüldü.

\section{TARTIŞMA}

Ülkemizde kanser tarama programında mide kanseri yer almamakla birlikte, ileri evre mide kanseri görülme ora- 
nı \%58 olarak belirtilmiştir (13). Çalışmamızda ameliyata aldığımız olgularımızın çoğunluğunun evre 3-4 $(\% 79,2)$ olduğu saptandı. İleri evre kanser oranı batı ülkelerinde $\% 30$ ve Japonya'da \%21'dir $(10,14)$. Mide kanserlerinde 5 yıllık sağ kalım oranları oldukça düşük olmakla beraber agresif tarama programları uygulayan ülkelerde erken tanı ile evre 1 ve 2 'deki olgularda 5 yıllık sağ kalım oranı \%70'lere ulaşmaktadır (15).

Dünya genelinde mide kanser prevalansında azalma bildirilmekle beraber, yaş grupları değerlendirildiğinde genç yaş grubunda premalign lezyonlar ve mide kanserinin prevalansında artma olduğu belirtilmiştir $(16,17)$. Ülkemizde mide kanseri prevalansının yıllar içinde değişimini değerlendirmek için yeterli veri bulunmamaktadır. Mide kanserlerinde insidansın dördüncü dekattan sonra artarak yedinci dekatta en üst düzeylere ulaştı̆ı̆, kadınlara göre erkeklerde iki kat daha sık görüldüğü belirtilmiştir (18). Olgularımızda da ileri yaş $(64,40 \pm 10,26)$ ve erkek cinsiyetin $(\% 71,4)$ ağırlıkta olduğu görüldü. Yaş grupları değerlendirildiğinde sadece $2(\% 2,6)$ olgunun 40 yaşından küçük olduğu, $24(\% 31,6)$ olgunun ise 70 yaşından büyük olduğu görüldü.

Mide kanserli olguların yaklaşık \%40'ı asemptomatik olup, erken tanı sıklıkla nonspesifik karın ağrısı ve dispepsi nedeniyle yapılan endoskopi esnasında tesadüfen konmaktadır (19). Olgularımızda tanı sürecinde en sık görülen semptomların epigastrik ağrı $(\% 54,5)$ ve kusma $(\% 22,1)$ olduğu saptandı. Bu semptomlar da genelde ileri bir hastalığın göstergesidir.

Mide kanserinde bilinen en iyi tedavi yöntemi küratif rezeksiyondur. Küratif rezeksiyon kitlenin temiz cerrahi sınırlarla ve yeterli bir bölgesel lenf nodu diseksiyonu ile birlikte çıkarımasıdır. Lenf nodu diseksiyonunun kapasamının nasıl olması gerektiği konusu yıllardır Batılı otörler ve Japon otörler arasında tartışma konusu olmuştur. Batıda önceleri birçok merkezde ileri evre mide kanserlerinde D2 lenf nodu diseksiyonunun (LND) yapılması -sağ kalıma fayda sağlamadığı gerekçesiyle ayrıca post operatif morbiditesi yüksek bir prosedür olması nedeniyle- önerilmiyordu. Ileri evre mide kanserinde D1 diseksiyon yöntemi rutin bir uygulama haline gelmişti. 1995 ve 1996 yıllarında Hollanda Gastrik Kanser Araştırması ve Tıbbi Araştırma Konseyi (MRC) Araştırması D1 ve D2 LND'den sonra erken sonuçları yayınladı $(20,21)$. Her iki çalışmada da D2 diseksiyonundan sonra morbidite ve mortalite oranları belirgin olarak daha yüksek bulunmuştur. Özellikle MRC çalışmasında yüksek morbidite, büyük oranda orta ve üst tümörler için D2 diseksiyonunun bir parçası olarak yapılan pankreas rezeksiyonları ve splenektomilere bağlıydı. 1999'da, bu iki prospektif randomize çalışmanın uzun dönem sonuçları yayınlandı ve D2 LND'den sonra uzun dönem sağkalım avantajının olmadığı bulundu. Genel ve hastalıksız sağkaIım veya rekürrens riski açısından uzun vadeli sonuçlarda bir gelişme yoktu (21). Daha sonraları Hollanda'daki bu araştırmanın 15 yıllık takip sonuçları, D2 lenfadenektominin D1 lenfadenektomiden daha düşük lokal bölgesel rekürrens ile (\%22'ye karşı \%12) ve gastrik kanserle ilişkili ölüm oranlarına (\%37'ye karşı \%48) bağlı olduğunu gösterdi (20). 15 yıllık sağkalım oranları sırasıyla D2 LND'da \%29 ve D1 LND'dan sonra \%21 idi. Pankreatosplenektomi uygulanmayan hastalar arasında D2 LND'den sonra sağkalım oranı D1 LND'den sonra olanlara göre anlamlı derecede yüksekti (\%35'e karşın \%22). Yazarlar, dalak koruyucu D2 LND'nin güvenli bir şekilde yapılabileceğini, D2'nin kapsam olarak rezeke edilebilir mide kanseri için önerilen lenfadenektomi tipi olduğuna karar verdiler (20).

Japon yazarlar ise 1960 ylllardan beri mide kanser cerrahisinde batıya göre daha agressif girişimler (D3 ve D4 lenf nodu diseksiyonları ve kombine organ rezeksiyonları) yapmış ve D2 lenf nodu diseksiyonunun mide kanserinin tedavisinde rutin olarak yapılması gereken bir işlem olduğunu ileri sürmüşlerdir (22). Ancak 2010 yılında yayınlanan Japon Gastrik Kanser Derneği'nin Japon Gastrik Kanser Tedavi Rehberi'nde (3. Ingilizce baskı) lenf nodu diseksiyonun genişliği konusunda daha ılımlı bir yaklaşıma doğru gittikleri ve hemen hemen batı yazarların yaklaşımına benzer yaklaşımları benimsedikleri görülmektedir (12). Günümüzde mide kanserinin tedavisinde kapsam olarak D1, D1+ ve D2 lenf nodu diseksiyonlarının yapılması önerilmektedir. Kliniğimizde lenf nodu diseksiyonunun genişliği Japon Gastrik Kanser Tedavi Rehberi (3. Ingilizce baskı) önerilerine göre yapılmaktadır (12). Olgularımıza tümörün T1-4 evresine göre D1+ veya D2 lenf nodu diseksiyonları uyguladık.

Illeri evre mide kanserlerinin \%3-27'sinde komşu organlara lokal invazyon nedeniyle kombine rezeksiyonlar gerekebilir (23). Olgularımızın \%10,4'ünde ek organ rezeksiyonu yaptık. En sık ek organ rezeksiyonu olarak splenektomi uygulandı. Günümüzde serozayı aşan tümörlerde rutin olarak splenektomi yapılması önerilmemektedir. Dutch çalışmasında D2 diseksiyon, splenektomi, pankreatektomi ve ileri yaş (70 yaş üstü) artmış morbidite ve mortalite ile ilişkili bulunmuştur (24). Splenektomi veya pankreatektomi 5 yıllık sağ kalımı değiştirmemekte olup, rutin rezeksiyonu önerilmemektedir $(25,26)$. Japon Gastrik Kanser Tedavi Rehberi (3. İngilizce baskı) büyük kurvatur boyunca lokalize olan tümörler ve 4 sb lenf bezlerinde metastaz varlığında splenektomi yapıımasını önermektedir (12).

Bursektomi daha önce serozal invazyonu olan tüm tümörler için önerilmişti. Ancak 2011'de yayınlanan yeni 
Japon Gastrik Kanser Tedavi Rehberi, bu tavsiyeyi posterior gastrik duvarın serozal penetrasyonu olan olgularla sınırlamaktadır (12). Biz serozal invazyonu olan hastalarda bursektomi yapmayı tercih ediyoruz.

Mide kanserli olgularda radikal rezeksiyon sonrası perioperatif morbidite oranı $\% 15$ ve mortalite oranı $\% 3$ olarak bildirilmiştir (27). Çalışmamızda benzer şekilde periopertaif morbidite $\% 11,6$ ve mortalite $\% 3,9$ olarak görüldü.

Minimal invaziv cerrahideki son gelişmelerin sonucu olarak, gastrik kanser için laparoskopik gastrektomi giderek artmaktadır. Laparoskopik mide rezeksiyonları intraoperatif kan kaybı, analjezik ihtiyacı, hastanede kalış süresi ve intestinal motilitenin başlama süresi gibi kısa dönemli sonuçları olumlu yönde etkilemektedir (28). Ancak ileri evre mide kanserleri için uygun bir prosedür olup olmadığı konusunda bir anlaşma sağlanmamıştır (29). Potansiyel kürabıl mide kanserlerinde laparoskopik evreleme yapılması önerilmektedir (30). Çalışmamızda 9 olguya laparoskopik rezeksiyon planlanmış 4 olgu işlemi laparoskopik olarak tamamlanmış ve 5 olguda konversiyon laparotomiye geçilmiştir. Bunun nedeni olarak sınılı hasta sayısı, cerrahi deneyimin azlığı ve ileri evre olguların opere edilmesi olduğu düşünüldü.

Mide kanserlerde tümörün patolojik evrelemesi sağ kalım tahmini açısından önemlidir. Beş yıllıı sağkalım T1 patolojik evrede yapılan rezeksiyon sonrası \%98, T2-4 tümörlerde \%38-59 arasında değişmektedir (31). Olgularımızda rezeksiyon piyeslerinin incelenmesi sonrası ağırlıklı olarak ileri patolojik evrelerin olduğu görüldü. Ülkemizde yapılan bir çalışma \%29,1'i evre IV ve \% 51,4'ü evre III'te hastalar bildirilmiştir (32). Çalışmamızda da Evre III \%61, Evre IV $\% 18,2$ hastanın yer aldığı görüldü. Evreler değerlendirildiğinde genel olarak olgularımızın başvuru anında \%79,2'sinin ileri evrede yer aldığı görüldü. Ülkemizde ve bölgemizde opere ettiğimiz ileri evre kanserli olgular göz önüne alındığında endoskopik tarama programları ile erken evre olguların saptanmasının gerekli olduğu düşünülmektedir.
Mide kanserini önlemede etiyolojik nedenlerin (Helicobacter pylori eradikasyonu, yaşam stili değişiklikleri) giderilmesi önem arzeder. Helicobacter pylori prevalansı gelişmiş ülkelerde $\% 30$, gelişmekte olan ülkelerde $\% 90$ seviyesindedir (33). Bölgemizde de Helicobacter pylori \%74,3 oranında görülmüştür (34). 1994 ylında Helicobacter pylori mide kanseri için klas 1 karsinojen olarak tanımlanmıştır (35). Helicobacter pylori gland kaybına neden olmakta, sırasıyla kronik aktif gastrit, atrofik gastrit, interstinal metaplazi ve displazi gelişmekte, kanser gelişimi son evrede görülmektedir (36). Helicobacter pylori eradikasyonunun intestinal metaplazi ve displazi zemininde gelişen mide kanser insidansında azalma olmasına neden olduğu, ancak mide kanser mortalitesinde azalmaya istatiksel olarak neden olmadığı belirtilmiştir (37).

Çalışmamızda birkaç sınırlama mevcuttur. Olgu sayısının nispeten az ve tek merkezli retrospektif bir çalışma olması, kanser teşhisi alan hastalarda Helicobacter pylori pozitiflıği nedeniyle tedavi alıp alamadıkları, tedavi sonrası re-enfeksiyon gelişimi veya antimikrobiyal rezistansın tam olarak ortaya konulamaması, rutin rezeksiyon piyeslerinin incelenmesinde Helicobacter pylori ve intestinal metaplazinin patoloji raporunda rutin belirtilmemesi, sağ kalım verilerinin çalısmada yer almaması limitasyona neden olmaktadır.

Mide kanseri nedeniyle ile ameliyat ettiğimiz olgularımız tanı sırasında genellikle ileri evrede olup, bu olgulara geniş çaplı mide rezeksiyonları ve lenf nodu diseksiyonları yapılmaktadır. Mide kanserinin ülkemizde kanser tarama programında olmaması, endoskopik olarak değerlendirme için başvurulacak merkez sayısının sınırlı olması gibi nedenlerle olgularımı sıklıkla tanı anında ileri evrede başvurmaktadır. Minimal cerrahi girişimlerin veya endoskopik girişimlerin daha sık uygulanabilmesi için tarama programları ile olguların erken evrede saptanması gereklidir.

\section{KAYNAKLAR}

1. Ferlay J, Soerjomataram I, Dikshit R, et al. Cancer incidence and mortality worldwide: sources, methods and major patterns in GLOBOCAN 2012. Int J Cancer 2015;136:E359-86.

2. Jemal A, Bray F, Center MM, et al. Global cancer statistics. CA Cancer J Clin 2011;61:69-90.

3. Yalçın B, Zengin N, Aydın F, et al. The clinical and pathological features of patients with gastric cancer in Turkey: A Turkish Oncology Group Study. Turk J Cancer 2006;36:108-15.

4. Karimi P, Islami F, Anandasabapathy S, et al. Gastric cancer: descriptive epidemiology, risk factors, screening, and prevention. Cancer Epidemiol Biomarkers Prev 2014;23:700-13.

5. D'Elia L, Rossi G, Ippolito R, et al. Habitual salt intake and risk of gastric cancer: a meta-analysis of prospective studies. Clin Nutr 2012;31:489-98.

6. Crew KD, Neugut Al. Epidemiology of gastric cancer. World J Gastroenterol 2006;12:354-62.

7. Oliveira C, Pinheiro H, Figueiredo J, et al. Familial gastric cancer: genetic susceptibility, pathology, and implications for management. Lancet Oncol 2015;16:e60-70.

8. Park JY, von Karsa L, Herrero R. Prevention strategies for gastric cancer: a global perspective. Clin Endosc 2014;47:478-89. 
9. Yüksel BC, Uçar NS, Yıldız Y, et al. Mide kanserinde standart D2 diseksiyona karşı D1 diseksiyonun mortalite ve morbidite çalışması. Ulus Cerrahi Derg 2009;25:87-91

10. Wanebo HJ, Kennedy BJ, Chmiel J, et al. Cancer of stomach. A patient care study by the American College of Surgeon. Ann Surg 1993;218:583-92.

11. Bretthauer M, Kalager M, Adami HO. Do's and don'ts in evaluation of endoscopic screening for gastrointestinal cancers. Endoscopy 2016:48:75-80.

12. Japanese Gastric Cancer Association. Japanese classification of gastric carcinoma: 3rd English edition. Gastric Cancer 2011;14:101-12.

13. Vural V, Saylam B, Çomçalı B, et al. D1 versus D2 dissection in gastric carcinoma: Evaluation of postoperative mortality and complications. Ulus Cerrahi Derg 2013;29:1-6.

14. Kodera $Y$, Yamamura $Y$, Torii $A$, et al. Postoperative staging of gastric carcinoma. A comparison between the UICC Stage Classification and the 12. edition of the Japanese General Rules for Gastric Cancer Study. Scand J Gastroenterol 1996;31:476-80.

15. Youn HG, An JY, Choi MG, et al. Recurrence after curative resec tion of early gastric cancer. Ann Surg Oncol 2010;17:448-54.

16. Camargo MC, Anderson WF, King JB, et al. Divergent trends for gastric cancer incidence by anatomical subsite in US adults. Gut 2011;60:1644-9.

17. Song H, Held M, Sandin S, et al. Increase in the prevalence of atrophic gastritis among adults age 35 to 44 years old in Northern Sweden between 1990 and 2009. Clin Gastroenterol Hepatol 2015; 13:1592-600.

18. Göçmen E, Kocaoğlu H. Mide kanseri epidemiyolojisi. T Klin J Surg 2000;5:161-2

19. Traynor OJ, Lennon J, Dervan P, et al. Diagnostic and prognostic problems in early gastric cancer. Am J Surg 1987;154:516-9.

20. Songun I, Putter $H$, Kranenbarg EM, et al. Surgical treatment of gastric cancer: 15-year follow-up results of the randomised nationwide Dutch D1D2 trial. Lancet Oncol 2010;11:439-49.

21. Bonenkamp JJ, Songun I, Hermans J, et al. Randomised comparison of morbidity after D1 and D2 dissection for gastric cancer in 996 Dutch patients. Lancet 1995;345:745-8.

22. Japanese Gastric Cancer Association. Japanese classification of gas tric carcinoma. 2nd English ed. Gastric Cancer 1998;1:10-24.

23. Derici $H$, Yaman İ, İşgüder AS, et al. Lokal ileri evre mide kanserinde kombine rezeksiyonlar. Türkiye Klinikleri J Med Sci 2006;26:514-21.
24. Hartgrink $\mathrm{HH}$, van de Velde $\mathrm{CJ}$, Putter $\mathrm{H}$, et al. Extended lymph node dissection for gastric cancer: who may beneit? Final results of the randomized Dutch gastric cancer group trial. J Clin Oncol 2004;22:2069-77.

25. Furukawa H, Hiratsuka M, Ishikawa O, et al. Total gastrectomy with dissection of lymph nodes along the splenic artery: a pancreas-preserving method. Ann Surg Oncol 2000;7:669-73.

26. Csendes A, Burdiles P, Rojas J, et al. A prospective randomized study comparing D2 total gastrectomy versus D2 total gastrectomy plus splenectomy in 187 patients with gastric carcinoma. Surgery 2002;131:401-7.

27. National Oesophago-Gastric Cancer Audit 2015. Healthcare Quality Improvement Partnership Ltd, 2015. http://www.hqip.org.uk/ resources/national-oesophagogastric-cancer-audit-report-2015/ (8 August 2016, date last accessed).

28. Deng Y, Zhang Y, Guo TK. Laparoscopy-assisted versus open distal gastrectomy for early gastric cancer: A meta-analysis based on seven randomized controlled trials. Surg Oncol 2015;24:71-7.

29. Haverkamp L, Ruurda JP, Offerhaus GJ, et al. Laparoscopic gastrectomy in Western European patients with advanced gastric cancer. Eur J Surg Oncol 2016;42:110-5.

30. Waddell T, Verheij M, Allum W, et al. Gastric cancer: ESMO-ESSO-ESTRO clinical practice guidelines for diagnosis, treatment and follow-up. Ann Oncol 2013;24:vi57-63.

31. Degiuli M, Sasako M, Ponti A, et al. Randomized clinical trial comparing survival after D1 or D2 gastrectomy for gastric cancer. Br J Surg 2014;101:23-31.

32. Kısaoğlu A, Özoğul B, Yıldırgan Mi, et al. Mide kanserinde cerrahi: 504 Olgu. Abant Med J 2014;3:220-5.

33. Goh KL, Chan WK, Shiota S, et al. Epidemiology of Helicobacter pylori infection and public health implications. Helicobacter 2011;16:1-9.

34. Cayci HM, Erdogdu UE, Karaman K, et al. Should endoscopy be routinely performed for bariatric surgery candidates? Eur Res J 2016;2:93-8.

35. Ishaq S, Nunn L. Helicobacter pylori and gastric cancer: a state of the art review. Gastroenterol Hepatol Bed Bench 2015;8:6-14.

36. Correa P, Haenszel W, Cuello C, et al. A model for gastric cancer epidemiology. Lancet 1975;2:58-60.

37. Li WQ, Ma JL, Zhang L, et al. Effects of Helicobacter pylori treatment on gastric cancer incidence and mortality in subgroups. J Natl Cancer Inst 2014;106. pii:dju116. 